\title{
Intention to use long-acting and permanent contraceptive methods and associated factors in health institutions of Aksum Town, North Ethiopia
}

\author{
Hailay Syum ${ }^{1 *}\left(\mathbb{D}\right.$, Gizienesh Kahsay ${ }^{\prime}$, Teklehaymanot Huluf', Berhe Beyene ${ }^{1}$, Hadgu Gerensea², \\ Gebreamlak Gidey ${ }^{3}$, Haftom Desta ${ }^{4}$, Mebrahtu Abay ${ }^{1}$, Haben Nuguse ${ }^{5}$ and Kebede Haile ${ }^{1}$
}

\begin{abstract}
Objective: In Ethiopia, the majority of married women practice predominantly short-acting contraceptive methods. Therefore this study aims to assess intention to use LAPMs and its determinants among short-acting users in Health Institutions of Aksum Town, North Ethiopia.

Results: Prevalence of intention to use LAPMs was 52.1\% (95\% Cl 47.4-57.0). Good knowledge on LAPMs $[A O R=2.15 ; 95 \% \mathrm{Cl}(1.29,3.56)]$, positive attitude towards LAPMs $[A O R=3.41 ; 95 \% \mathrm{Cl}(1.99,5.85)]$, $18-24$ years of age $[A O R=3.18 ; 95 \% \mathrm{Cl}(1.30,7.79)]$, being primary school in educational level $[\mathrm{AOR}=0.34 ; 95 \% \mathrm{Cl}(0.14,0.78)]$, decision on the number of children jointly with partner $[A O R=2.05 ; 95 \% \mathrm{Cl}(1.01,4.18)]$, having more than two children $[\mathrm{AOR}=10.67 ; 95 \% \mathrm{Cl}(1.29,88.31)]$, and no $[\mathrm{AOR}=10.21 ; 95 \% \mathrm{Cl}(3.10,33.58)]$ and one $[\mathrm{AOR}=4.70 ; 95 \% \mathrm{Cl}(1.68$, 13.13)] extra number of children desired were factors significantly associated with having intention to use LAPMs compared to their counterparts. The intention to use LAPMs was low. Therefore, appropriate information, education and communication strategies must be designed to raise awareness and change the negative attitude of the community on LAPMs.
\end{abstract}

Keywords: LAPMs, Intention to use, Factors, Axum, Ethiopia

\section{Introduction}

Family planning (FP) enables couples to determine whether, when, and how often to have children. Thereby it benefits everyone; women are healthier, more prosperous and have greater opportunities to pursue education and careers. Their children are stronger, better nourished and more successful in school. Families and communities can invest more in education and health care. Poverty is reduced; lives are saved $[1,2]$.

To envision the health benefits, evidence suggests that meeting the need for modern contraception among women in the developing region could prevent 1.6

\footnotetext{
*Correspondence: hailayaku@gmail.com

1 School of Public Health, College of Health Science and Comprehensive Specialized Hospital, Aksum University, Aksum, Ethiopia

Full list of author information is available at the end of the article
}

million newborn deaths and 170,000 maternal deaths each year [3]. Therefore, it is very important to meet the FP need of the population and provide universal access to a full range of safe and reliable FP methods [1-3].

Notwithstanding the strikingly well-known and fascinating benefits, more than 225 million (26\%) women who want to avoid pregnancy in a developing world still lack access to effective methods of contraception [3]. The FP need for $53 \%$ of the married women in Africa is unmet, which is two times higher than the average unmet need in the developed world $[4,5]$. Even among the vast majority of the FP users in the developing world, the method is short-acting, which is less effective $[1,6,7]$. A total of 289,000 women per 100,000 live births per year and more than 7000 newborns per day die globally from very preventable problems that could have been deterred 
markedly through FP. Developing countries, mainly subSaharan Africa and South Asia, accounted for $80 \%$ of these deaths $[3-5,8,9]$.

In Ethiopia, the unmet need for FP is $25 \%$. Furthermore, the majority of the FP users in Ethiopia use shortacting methods of contraception. The long-acting and permanent methods of contraception, the most effective in preventing pregnancy, remained least used [10].

Intentions to perform a behavior translate into actual behavior when environmental obstacles can be overcome and individuals have skills to perform the behavior [11]. Hence, the intention to use LAPMs is the most important determinant of using the method $[12,13]$. However, different individual and environmental factors may affect intention to use LAPMs. As indicated by some studies conducted elsewhere; socio-demographic characteristics, reproductive health characteristics, knowledge, attitude, myths, and misconceptions may affect it [14-19].

Given the prevailing low utilization of LAPMs in Ethiopia, an analysis of use intention and a critical assessment of the underlying factors are important. Because the generated inputs would have an imperative role in designing effective programs to solve the prevailing low level of LAPMs use. However, little has been documented so far in the aforementioned issue in Ethiopia. Thus, this study was conducted to assess the intention to use LAPMs and its determinants among married women of reproductive age in Axum Town, Northern Ethiopia.

\section{Main text Methods \\ Study design, period and setting}

The study area was Aksum Town. Aksum is found in the Central zone of Tigray regional state located $1025 \mathrm{~km}$ north of Addis Ababa. Aksum has a total population of 60,706 . The number of the female population in Aksum is 30,657 of these 12,214 are women in the reproductive age group. Aksum has one referral hospital, two governmental health centers, and one local NGO clinic; all of them provide maternal health services. An institution-based cross-sectional study was conducted. The study was conducted from February to March 2016.

\section{Source population}

The source population was all women who are short-acting contraceptive users of health institutions of Aksum Town.

\section{Study population}

The study population was all women who are short-acting contraceptive users that visited health institutions of Aksum Town during the study period.

\section{Inclusion and exclusion criteria}

Inclusion criteria All women who are on short-acting contraceptive methods in health institutions of Aksum Town.

\section{Exclusion criteria No exclusion criteria.}

\section{Sample size determination}

The sample size was calculated using a single population proportion formula with the assumption margin of error is $5 \%$, and the confidence level is $95 \%$. The prevalence of intention to use LAPMs was used $48.4 \%$ [15]. The calculated sample size was 384 . Adding none response rate $5 \%$ the final sample size used was 403 .

\section{Sampling procedure}

The total sample size was divided proportionally to the four health institutions based on their client flow. The proportionally allocated sample size was Aksum St. Merry Hospital $=216$, Aksum Health Center $=105$, Millennium Health Center $=49$, and Family Guidance Association of Ethiopia (FGAE) clinic $=33$. The study participants were taken by systematic random sampling, every 2 nd of the clients $(\mathrm{k}=2.1)$ and the 1 st client was selected by simple random sampling from 1 and 2 .

\section{Operational definition}

Intention to use LAPMs Desire to use long-acting and permanent contraception methods as reported by the study participant.

Knowledge about LAPMs Ten awareness questions (with 'Yes/No' answers) were included [19, 20]. The score is calculated by adding values given to each of the ten questions. Then, it was categorized as low knowledge and good knowledge based on the mean score.

Attitude about LAPMs Ten questions (with 'Yes/No' answers) were included. An attitude score was computed using the same procedure that was used to compute the knowledge score. Then, it was categorized as a negative attitude and Positive attitude based on the mean score.

\section{Data collection procedure}

A structured pre-tested questionnaire, prepared via reviewing of literature, was used. The questionnaire was initially prepared in English and translated into Tigrigna (local language) and again retranslated back to English to check for any inconsistencies or distortions in the meaning of words and concepts. Face to face interview was the technique of data collection (Additional file 1). For administering the interview four diploma nurses, data collectors, were recruited. 


\section{Data quality control}

To assure data quality the data collection tool was translated into the local language. The recruited data collectors were trained for 2 days on the tool, objectives, confidentiality of the study. The structured questionnaire was pre-tested on $5 \%$ of the sample size outside of the study area, in Laelay Maychew district. Close supervision was undertaken during data collection.

\section{Data processing and analysis}

All collected data were entered into EPI-info version 7 and transferred to SPSS version 20 statistical software for its analysis. Data were cleaned and coded for completeness and consistency. A binary logistic regression model was used for analysis. Factors associated with intention to use LAPMs at bivariable analysis were identified and the variables with a P-value of 0.20 and less were fit to logistic model for multivariable analysis to determine relative prediction level of independent variables to the outcome variable. A P-value less than 0.05 at $95 \%$ confidence interval was considered as statistically significant. Model goodness-of-fit was checked by the Hosmer-Lemeshow test.

\section{Results}

\section{Socio-demographic characteristics}

A total of 384 women participated in the study with a response rate of $95.3 \%$. The ages of respondents were ranged from 18 to 45 years with the mean age of 30.3 $(\mathrm{SD} \pm 6.8)$ years, and about one-third of the women 121 (31.5\%) were in the age group $\geq 35$ years. Almost all of the respondents 381 (99.2\%) were Tigray in Ethnicity and 370 (96.4\%) were Orthodox Christians in religion (Table 1).

\section{Reproductive characteristics}

The mean ideal desired number of children of the participant was $2( \pm 1.2 \mathrm{SD})$ and the decision on the number of children to have was decided jointly by the husband and wife in 317 (82.6\%) of the participants (Table 2).

\section{The magnitude of intention to use LAPMs}

More than half 200 (52.1\%), (95\% CI 47.4-57.0\%) of the 384 women had the intention to use LAPMs in health institutions of Aksum Town.

\section{Factors associated with intention to use LAPMs}

According to this study factors that were associated with intention to use LAPMs on bivariable analysis at the level of P-value 0.2 and less were fit into a multivariable logistic regression model. The multivariable analysis result of this study declared that knowledge on LAPMs, attitude on LAPMs, age, education, number of children desired, a decision on the number of children
Table 1 Socio-demographic characteristics of women utilizing short acting family planning service in health institutions, Axum town, northern Ethiopia, March, 2016 $(\mathrm{n}=384)$

\begin{tabular}{lcc}
\hline Variables & Frequency & Percent \\
\hline Age in years & 87 & \\
$18-24$ & 176 & 22.7 \\
$25-34$ & 121 & 45.8 \\
$\geq 35$ & & 31.5 \\
Religion & 370 & \\
Orthodox & 14 & 96.4 \\
Muslim & & 3.6 \\
Household size & 259 & \\
1-4 & 125 & 67.4 \\
5-10 & & 32.6 \\
Marital status & 358 & \\
Married & 26 & 93.2 \\
Single & & 6.8 \\
Mothers'education & 65 & 16.9 \\
No formal education & 81 & 21.1 \\
Primary school & 141 & 36.7 \\
Secondary school & 97 & 25.3 \\
Post secondary & & \\
Mothers'occupation & 56.2 & 11.7 \\
House wife & 93 & \\
Private business & & \\
Employed & & \\
Unemployed & & \\
\hline
\end{tabular}

Table 2 Reproductive characteristic of women utilizing short acting family planning service in health institutions, Axum town, northern Ethiopia, March, 2016 ( $n=384$ )

\begin{tabular}{lrl}
\hline Variables & Frequency & Percent \\
\hline History of abortion & 51 & \\
Yes & 333 & 13.3 \\
No & & 86.7 \\
Number of abortions & 333 & \\
0 & 51 & 86.7 \\
$1-2$ & & 13.3 \\
Number of children alive & 260 & \\
$<2$ & 124 & 67.7 \\
$>2$ & & 32.3 \\
Desire for more child & 328 & \\
Yes & 56 & 85.4 \\
No & & 14.6 \\
Number of desired children & 56 & \\
0 & 77 & 14.6 \\
1 & 122 & 20.1 \\
2 & 80 & 31.8 \\
3 & 49 & 20.8 \\
$4-6$ & & 12.8 \\
\hline
\end{tabular}


Table 3 Bivariable and multivariable analysis of associated factors of intention to use LAPMs of women in health institutions of Axum town, northern Ethiopia, March, $2016(n=384)$

\begin{tabular}{|c|c|c|c|c|}
\hline \multirow[t]{3}{*}{ Variables } & \multicolumn{2}{|c|}{ Intention to use LAPMs } & \multicolumn{2}{|l|}{ OR } \\
\hline & Yes & No & COR & AOR $(95 \% \mathrm{Cl})$ \\
\hline & Number (\%) & Number (\%) & & \\
\hline \multicolumn{5}{|l|}{ Knowledge on LAPMs } \\
\hline Low knowledge & $65(37.6 \%)$ & $108(62.4 \%)$ & 1.00 & 1.00 \\
\hline Good knowledge & $135(64 \%)$ & $76(36 \%)$ & $2.95^{* * *}$ & $2.15(1.29,3.56)^{* *}$ \\
\hline \multicolumn{5}{|l|}{ Age of mothers } \\
\hline 18-24 years & $59(67.8 \%)$ & $28(32.2 \%)$ & $2.37^{* *}$ & $3.18(1.30,7.79)^{*}$ \\
\hline $25-34$ years & $84(47.7 \%)$ & $92(52.3 \%)$ & 1.03 & $1.19(0.60,2.35)$ \\
\hline$\geq 35$ years & $57(47.1 \%)$ & $64(52.9 \%)$ & 1.00 & 1.00 \\
\hline \multicolumn{5}{|l|}{ Mothers' education } \\
\hline No formal education & $27(41.5 \%)$ & $38(58.5 \%)$ & 0.57 & $0.70(0.27,1.80)$ \\
\hline Primary school & $31(38.3 \%)$ & $50(61.7 \%)$ & $0.49^{*}$ & $0.34(0.14,0.78)^{*}$ \\
\hline Secondary school & $88(62.4 \%)$ & $53(37.6 \%)$ & 1.32 & $1.06(0.50,2.25)$ \\
\hline Post secondary & $54(55.7 \%)$ & $43(44.3 \%)$ & 1.00 & 1.00 \\
\hline \multicolumn{5}{|c|}{ Number of children desired } \\
\hline 0 & $32(57.1 \%)$ & $24(42.9 \%)$ & 1.28 & $10.21(3.10,33.58)^{* * *}$ \\
\hline 1 & $45(58.4 \%)$ & $32(41.6 \%)$ & 1.35 & $4.70(1.68,13.13)^{* *}$ \\
\hline 2 & $65(53.3 \%)$ & $57(46.7 \%)$ & 1.10 & $1.95(0.84,4.52)$ \\
\hline 3 & $33(41.2 \%)$ & $47(58.8 \%)$ & 0.67 & $0.75(0.32,1.80)$ \\
\hline $4-6$ & $25(51 \%)$ & $24(49 \%)$ & 1.00 & 1.00 \\
\hline \multicolumn{5}{|c|}{ Decision on the number of children } \\
\hline Myself & $23(34.3 \%)$ & $44(65.7 \%)$ & 1.00 & 1.00 \\
\hline Together & $177(55.8 \%)$ & $140(44.2 \%)$ & $2.42^{* *}$ & $2.05(1.01,4.18)^{*}$ \\
\hline \multicolumn{5}{|l|}{ Religion } \\
\hline Orthodox & $196(53 \%)$ & $174(47.0 \%)$ & 2.82 & $0.71(0.18,2.78)$ \\
\hline Muslim & $4(28.6 \%)$ & $10(71.4 \%)$ & 1.00 & 1.00 \\
\hline \multicolumn{5}{|l|}{ Attitude on LAPMs } \\
\hline Negative attitude & $40(29.4 \%)$ & $96(70.6 \%)$ & 1.00 & 1.00 \\
\hline Positive attitude & $160(64.5 \%)$ & $88(35.5 \%)$ & $4.36^{* * *}$ & $3.41(1.99,5.85)^{* * *}$ \\
\hline \multicolumn{5}{|c|}{ Heard myths and misconceptions } \\
\hline Yes & $131(55.0 \%)$ & $107(45.0 \%)$ & 1.37 & $1.06(0.64,1.74)$ \\
\hline No & $69(47.3 \%)$ & $77(52.7 \%)$ & 1.00 & 1.00 \\
\hline \multicolumn{5}{|l|}{ Household size } \\
\hline $1-4$ & $141(54.4 \%)$ & $118(45.6 \%)$ & 1.34 & $0.22(0.03,1.70)$ \\
\hline $5-10$ & $59(47.2 \%)$ & $66(52.8 \%)$ & 1.00 & 1.00 \\
\hline \multicolumn{5}{|l|}{ Number of children alive } \\
\hline$\leq 2$ & $142(54.6 \%)$ & $118(45.4 \%)$ & 1.37 & $10.67(1.29,88.31)^{*}$ \\
\hline$>2$ & $58(46.8 \%)$ & $66(53.2 \%)$ & 1.00 & 1.00 \\
\hline \multicolumn{5}{|l|}{ Mothers occupation } \\
\hline House wife & $100(52.6 \%)$ & $90(47.4 \%)$ & 0.74 & $0.46(0.19,1.07)$ \\
\hline Private business & $23(41.1 \%)$ & $33(58.9 \%)$ & 0.47 & $0.44(0.16,1.22)$ \\
\hline Employed & $50(53.8 \%)$ & $43(46.2 \%)$ & 0.78 & $0.53(0.21,1.35)$ \\
\hline Unemployed & $27(60.0 \%)$ & $18(40.0 \%)$ & 1.00 & 1.00 \\
\hline
\end{tabular}

* Statistically significant at $\mathrm{P}<0.05,{ }^{* *}$ statistically significant at $\mathrm{P}<0.01$, and ${ }^{* * *}$ statistically significant at $\mathrm{P}<0.001 ; O R$ odds ratio, AOR Adjusted Odds Ratio, COR Crude Odds Ratio; no formal education includes illiterate and able to read and write

and the number of children alive had a statistically significant association with intention to use LAPMs (Table 3).

\section{Discussion}

The finding of this study showed that $52.1 \%$ (95\% CI 47.4-57) women reported that they had the intention to 
use LAPMs. This finding is in line with the study done in Adigrat town (48.4\%) which is found in Northern Ethiopia [15].

It is a little higher in proportion to the study conducted in Debre Markos town, northwest Ethiopia (45.9\%) [20]. This might be due to the study participants and design difference in both studies, in Debremarkos town only married women participated and the design was community-based whereas in this study the participants were women short-acting family planning users.

It is higher in proportion to the study conducted in Welita Zone, Southern Ethiopia (38\%). This discrepancy could be explained by the difference in the study areas, and access to information and the services [16].

In this study, it was noted that knowledge of LAPMs was significantly associated with the intention to use LAPMs. Those women who had good knowledge of LAPMs were 2.5 times more likely (AOR 2.48; CI 1.55, 3.96) to have intention on LAPMs than women who had low knowledge of LAPMs. It was similar to the study conducted in Adigrat town [15]. This might be evident that knowledge is a prerequisite to intension.

Women aged 18-24 years were 5.3 times more likely (AOR 5.35; 95\% CI 2.40, 11.91) to have the intention to use LAPMs compared to women whose age is $\geq 35$ years. It was similar to the study conducted in Debre Markos town, northwest Ethiopia [20]. This could be because young women might get information on LAPMs better than the elder ones.

Women whose educational level post-secondary were about 2.4 times more likely (AOR 4.94; 95\% CI 1.74, 14.01) to have intention than those women who didn't attend formal education. It was in line with the study conducted in Nekemte town, Western Ethiopia [17], Wolaita Zone, Southern Ethiopia [16], Debre Markos town, northwest Ethiopia [20]. This implies that education has the pervasive impacts on women's intention to use LAPMs since it empowers women with knowledge and positive attitude on contraceptive methods and hence, increases predisposition to their intention and use of LAPMs.

In this study, it was revealed that the number of children desired was significantly associated with the intention to use LAPMs (AOR 6.02; CI 2.10, 17.30). Women who had no desire for more children were six times more likely to have the intention to use LAPMs compared to those women who had the desire 4-6 more children. It was in line with the study conducted in Adigrat town, Northern Ethiopia [20]. This could be explained by the participants' fear of fertility return after the use of long-acting methods. Not having a desire for more children was a significant predictor of intention to use contraceptives [18].

\section{Conclusion}

In this study prevalence of intention to use LAPMs was low, 52.1\%. The findings of this study showed that knowledge on LAPMs, attitude on LAPMs, age, education, number of children desired, decision on the number of children and numbers of children alive were significantly associated independent factors of the recent intention to use LAPMs among women who use short-acting contraceptive methods in health institutions of Aksum Town.

\section{Limitations}

As the study design is cross-sectional, the identified factors for intention to use LAPMs might not precede the outcome intention to use.

\section{Supplementary information}

Supplementary information accompanies this paper at https://doi. org/10.1186/s13104-019-4769-z.

Additional file 1. A questionnaire used to collect data on intention to utilize long acting contraception among women attending health institutions of Aksum town, Ethiopia.

\section{Abbreviations}

AOR: Adjusted Odd Ratio; Cl: confidence interval; FGAE: Family Guidance Association of Ethiopia; FP: family planning; LAPMs: long-acting and permanent contraceptive methods; SPSS: Statistical Package for Social Sciences.

\section{Acknowledgements}

Authors' gratitude goes to Aksum University, Aksum St. Merry hospital, Aksum Town health office, and FGAE for their cooperation and support during data collection. Last but not least we would like to thank the respondents for their time and valuable information.

\section{Authors' contributions}

HS developed the proposed idea of the research. HS, TH, GG, HG, HD, HN and GK get involved in proposal write up, data collection process and analysis. HS, $\mathrm{MA}, \mathrm{KH}$ and $\mathrm{BB}$ participated in formal data analysis and manuscript write up. All authors write the final manuscript. All authors read and approved the final manuscript.

\section{Funding}

There is no funding for this research. All costs of data collection and analysis were covered by the authors.

\section{Availability of data and materials}

The data and materials used for analysis and conclusions are available in the manuscript as supplementary data.

\section{Ethics approval and consent to participate}

Ethical clearance was obtained from IRB (Institution Review Board) of Aksum University College of Health Sciences with IRB number 011/2016 and official permission was obtained from Aksum St. Merry hospital, Aksum town health office, and FGAE. Written informed consent was obtained from each study participant to confirm willingness for participation after explaining the objective, procedure, advantage, and disadvantage of the study. Confidentiality of the information was maintained throughout by excluding names, keeping their privacy during the interview, and by interviewing them alone. Participants had the right to withdraw any time from the interview. 


\section{Consent to publish \\ Not applicable.}

\section{Competing interests}

This manuscript maintains no competing financial interest declaration from any person or organization, or non-financial competing interests such as political, personal, religious, ideological, academic, intellectual, commercial or any other. All authors declare that they have no competing interests.

\section{Author details}

${ }^{1}$ School of Public Health, College of Health Science and Comprehensive Specialized Hospital, Aksum University, Aksum, Ethiopia. ${ }^{2}$ School of Nursing, College of Health Science and Comprehensive Specialized Hospital, Aksum University, Aksum, Ethiopia. ${ }^{3}$ Department of Midwifery, College of Health Science and Comprehensive Specialized Hospital, Aksum University, Aksum, Ethiopia. ${ }^{4}$ Department of Psychiatry Nursing, College of Health Science and Comprehensive Specialized Hospital, Aksum University, Aksum, Ethiopia. ${ }^{5}$ School of Medicine, College of Health Science and Comprehensive Specialized Hospital, Aksum University, Aksum, Ethiopia.

Received: 18 August 2019 Accepted: 29 October 2019

Published online: 09 November 2019

\section{References}

1. Brown W, Druce N, Bunting J, Radloff S, Koroma D, Gupta S, et al. Developing the "120 by 20" goal for the Global FP2020 Initiative. Stud Fam Plan. 2014;45(1):73-84.

2. Casterline JB, Sinding SW. Unmet need for family planning in developing countries and implications for population policy. Popul Dev Rev. 2000;26(4):691-723.

3. Darroch JE, Singh S, Weissman E. Adding it up: the costs and benefits of investing in sexual and reproductive health 2014-estimation methodology. Appendix B: estimating sexual and reproductive health program and systems costs. New York: Guttmacher Institute; 2016.

4. Lomazzi M, Borisch B, Laaser U. The Millennium Development Goals: experiences, achievements and what's next. Global health action. 2014;7(1):23695

5. Union A. Common African Position (CAP) on the post-2015 development agenda. Addis Ababa: Union A; 2014.

6. Van Lith LM, Yahner M, Bakamjian L. Women's growing desire to limit births in sub-Saharan Africa: meeting the challenge. Glob Health Sci Pract. 2013;1(1):97-107.

7. Trussell J, Guthrie K. Choosing a contraceptive: efficacy, safety, and personal considerations. Hatcher RA, Trussell J, Nelson AL, Cates W, Stewart
FH, Kowal D Contraceptive technology, 19th revised edn. New York: Ardent Media, Inc. 2007:19-47.

8. You D, New JR, Wardlaw T. Levels and trends in child mortality. Report 2012. Estimates developed by the UN Inter-agency Group for Child Mortality Estimation; 2012.

9. Ahmed S, Li Q, Liu L, Tsui AO. Maternal deaths averted by contraceptive use: an analysis of 172 countries. Lancet. 2012;380(9837):111-25.

10. Federal Democratic Republic of Ethiopia. The 2016 Ethiopian Demographic and Health Survey (2016 EDHS) 2017. Available from: https:// dhsprogram.com/pubs/pdf/FR328/FR328.pdf.

11. Fishbein M, Cappella JN. The role of theory in developing effective health communications. J Commun. 2006;56(suppl_1):S1-17.

12. Ross JA, Winfrey WL. Contraceptive use, intention to use and unmet need during the extended postpartum period. Int Fam Plan Perspect. 2001;27:20-7.

13. Roy T, Ram F, Nangia P, Saha U, Khan N. Can women's childbearing and contraceptive intentions predict contraceptive demand? Findings from a longitudinal study in central India. Int Fam Plan Perspect. 2003. https:// doi.org/10.1363/ifpp.29.025.03.

14. Tanfer K, Wierzbicki S, Payn B. Why are US women not using long-acting contraceptives? Fam Plan Perspect. 2000;32:176-91.

15. Gebremariam A, Addissie A. Intention to use long-acting and permanent contraceptive methods and factors affecting it among married women in Adigrat town, Tigray, Northern Ethiopia. Reprod Health. 2014;11(1):24

16. Meskele M, Mekonnen W. Factors affecting women's intention to use long-acting and permanent contraceptive methods in Wolaita Zone, Southern Ethiopia: a cross-sectional study. BMC Women's Health. 2014;14(1):109.

17. Tekelab T, Sufa A, Wirth D. Factors affecting intention to use long-acting and permanent contraceptive methods among married women reproductive age groups in Western Ethiopia: a community-based crosssectional study. Fam Med Med Sci Res. 2015;4(158):2.

18. Agha S. Intentions to use contraceptives in Pakistan: implications for behavior change campaigns. BMC Public Health. 2010;10(1):450.

19. Bulto GA, Zewdie TA, Beyen TK. Demand for long-acting and permanent contraceptive methods and associated factors among married women of the reproductive age group in Debre Markos Town, North West Ethiopia. BMC Women's Health. 2014;14(1):46.

20. Abajobir A. Intention to use long-acting and permanent family planning methods among married 15-49 years Women in Debremarkos Town, Northwest Ethiopia. Fam Med Med Sci Res. 2014;3(145):2.

\section{Publisher's Note}

Springer Nature remains neutral with regard to jurisdictional claims in published maps and institutional affiliations.
Ready to submit your research? Choose BMC and benefit from:

- fast, convenient online submission

- thorough peer review by experienced researchers in your field

- rapid publication on acceptance

- support for research data, including large and complex data types

- gold Open Access which fosters wider collaboration and increased citations

- maximum visibility for your research: over $100 \mathrm{M}$ website views per year

At BMC, research is always in progress.

Learn more biomedcentral.com/submissions 